\title{
Immunodeficient Mouse Models: An Overview
}

\author{
José E. Belizário* \\ Department of Pharmacology, Institute of Biomedical Sciences, University of São Paulo, SP, CEP 05508-900, Brazil
}

\begin{abstract}
The development and use of an increasing number and variety of naturally, transgenic, induced mutant, and genetically engineered immunodeficient mouse and mouse/human hybrids models have been imperative for understanding the gene-driven cellular and molecular mechanisms and pathophysiological manifestations (phenotypes) of immune disorders that are similar to mice and humans. Much more effort is needed to develop new system models to promote the integration of thousands of genes and their variants that are likely to affect the outcome of microbial infections, immune deficiency and autoimmunity. This article provides an update on characteristics and applications of most commonly used inbred and new hybrid strains of naturally immunodeficiency, knockout and transgenic mouse models, and a short discussion on how innovative technologies and databases presently available can be used for devising new models to better understand the human immune system and diseases that affect it.
\end{abstract}

Keywords: Animal models, immune system, immunodeficiency, xenografts.

\section{INTRODUCTION}

Modeling the immune response and rational immune approaches in vivo have relied heavily on basic studies performed in transgenic and immunodeficient mice models [1]. The creation of chimaeras of mouse-human models that successfully engrafted and developed all human myeloid and migrate into host organs and tissues have provided helpful assay system for novel vaccines and therapeutic agents [1]. Additionally, the expression of human genes in these mouse models have optimized their use for investigation of perturbations in populations of T and B cells and cytokine and chemokine protein expression in response to many diseases and infection contexts, in different tissues and at different times [1]. Conventional immunological approaches and DNA and protein high-throughput methods have been applied for correlating genotype to immunological phenotype of a model. In addition, customized immunological phenotyping in mouse models has been established using a high-throughput real-time PCR strategy for quantitative expression of immune genes [2]. Through this method, a unique "gene molecular signature" has been established for rheumatoid arthritis, systemic lupus erythematosus and graft versus host diseases [2]. These initial studies suggest the usefulness of such a method for many other immune-related diseases. More recently, gene ontology (GO) annotation for immunologically related genes in human, mouse and other species has been publicity available and can be easily retrieved via the internet from the GO Consortium [http://www.geneontology.org, http://www.wiki. geneontology.org and http://www.jax.org]. Overall these improvements and approaches will overcome some limitations of using these models to carry out in vivo studies leading to advances of our understanding of the immune system and diseases caused by its dyregulation.

\footnotetext{
*Address correspondence to this author at the Department of Pharmacology, ICB, USP, Avenida Lineu Prestes, 1524 CEP 05508-900, São Paulo, SP, Brazil; Fax: 55-11-3091 7318; E-mail: jebeliza@usp.br
}

There is a relatively high number of strains and substrains of natural immunodeficiency models and gene deficient transgenic models available for genetic and immunological studies [http://www.jax.org/pub-cgi/imsrlist, http://imsr.har.mrc.ac.uk/, http://www.apf.edu.au/index.shtml, http://www.brc.riken.jp/lab/animal/en]. The strains have specific deficiencies in MHC class I, II or both; B cell or T cell defects, or defects in both, as well as immunodeficiency due to knockdown of genes for cytokines, cytokine receptors, TLR receptors and a variety of transducers and transcription factors of signaling pathways [3-7]. The use of these inbred strains has contributed to identifying hundreds of genes responsible for controlling the outcome of microbial infections and to understanding fundamental questions in the molecular control of immune deficiency or autoimmunity.

Immunodeficiency mouse models include the single-gene mutation models such as nude-mice $(n u)$ strains and the severe combined immunodeficiency (scid) strains, non-obese diabetic (NOD) strain, RAG (recombination activating gene) strains with targeted gene deletion and a variety of hybrids originated by crossing doubly and triple mutation mice strains with additional defects in innate and adaptive immunity $[1,7]$. For the efficient use of these models, it is describe below some specific immunological and physiological characteristics of the most important strains available. Table 1 offers a brief review of the mutation phenotype and application for each model described.

Nude Strains. The first BALB/c Nude $(n u)$ mouse with the absence of hair and a thymus was described by Flanagan in 1966 [8]. A single-gene mutation produced a hairless state which gives the nickname "nude". In 1966 it was discovered that this mutation also produces an athymic - lack of functional thymus - state in homozygotes. A nude mouse is a genetic mutant that has a deteriorated or removed thymus gland, resulting in a lack of body hair and an inhibited immune system due to a greatly reduced number of $\mathrm{T}$ cells. The genetic basis of the nude mouse mutation is a disruption of the Foxn 1 gene or the HNF-3/forkhead homolog 11 gene 
Table 1. Spontaneous and Transgenic Immunodeficient Mouse Models and Applications

\begin{tabular}{|c|c|c|c|}
\hline Mouse Strain & Immune Deficiency & Applications & References \\
\hline Nude $(n u)$ & $\begin{array}{l}\text { The mutation at Foxn1 (winged-helix/forkead transcrition } \\
\text { factor) gene blocks thymus-derived T cells. Mice are } \\
\text { athymic, however, they have highly activated NK cells. }\end{array}$ & $\begin{array}{l}\text { Transplantation of murine and human (xenogenic) } \\
\text { tumors for imaging, metastasis and new therapies } \\
\text { studies. }\end{array}$ & {$[8,9]$} \\
\hline Scid (scid) & $\begin{array}{l}\text { The mutation at Prkdc/scid (protein kinase, DNA activated, } \\
\text { catalytic polypeptide) protein necessary for joining non- } \\
\text { homologous ends of double-stranded DNA. CB17-scid } \\
\text { mice have spontaneous generation of mouse T and B cells } \\
\text { (immunoglobulin leakiness) with age and are very sensitive } \\
\text { to irradiation. }\end{array}$ & $\begin{array}{l}\text { Transplantation of murine and human (xenogenic) } \\
\text { tumors for imaging, metastasis and new therapies } \\
\text { studies. Low levels of engraftment of human PBMC } \\
\text { and fetal hematopoietic tissues (HSCs). }\end{array}$ & [12-14] \\
\hline NOD & $\begin{array}{c}\text { Lack of expression for the major histocompatibility } \\
\text { complex (MHC) haplotype named } \mathrm{H}-2^{\mathrm{g} 7} \text { and SNP in } \\
\text { CTLA-4 gene, which are essential for diabetes-induced } \\
\text { autoimmunity. }\end{array}$ & $\begin{array}{l}\text { Studies of various tolerogenic processes and } \\
\text { autoantibodies involved in spontaneous autoimmune } \\
\text { diabetes. }\end{array}$ & {$[10,11]$} \\
\hline $\begin{array}{l}\text { RAG } 1 \text { and } \\
\text { RAG2 (rag) }\end{array}$ & $\begin{array}{c}\text { The deletion of Ragl or Rag2 (recombination activating } \\
\text { genes) cause the arrest of rearrangement of B cell receptors } \\
\text { (immunoglobulin production) and T cell receptors and } \\
\text { absence of T and B cell differentiation. These mice have } \\
\text { high levels of NK-cell activity but do not show } \\
\text { immunoglobulin leakiness and they are less sensitive to } \\
\text { radiation. }\end{array}$ & $\begin{array}{l}\text { Functional analysis of rag genes, molecular and } \\
\text { cellular mechanism of lymphoid differentiation and } \\
\text { blastocyst complementation assay. }\end{array}$ & {$[15,16]$} \\
\hline NOD-scid & $\begin{array}{c}\text { These animals are both insulitis- and diabetes free. Because } \\
\text { of interaction of multiple genes referred as insulin- } \\
\text { dependent susceptibility genes and Prkdc/scid gene } \\
\text { mutation, they show many innate immune defects, } \\
\text { including NK cell dysfunction, low cytokine production } \\
\text { and T and B cell dyregulation. Only } 10 \% \text { of mice display } \\
\text { immunoglobulin leakiness. }\end{array}$ & $\begin{array}{l}\text { Higher levels of engraftment of PBMC and } \\
\text { hematopoeitic stem cells (HSCs) compared with the } \\
\text { scid deficiency models. }\end{array}$ & {$[14,17-19]$} \\
\hline IL2rgnull & $\begin{array}{l}\text { Deletion of the IL-2 receptor } \gamma \text {-chain impairs multiple } \\
\text { cytokine signaling and leads to complete block of T and B } \\
\text { cell development. }\end{array}$ & $\begin{array}{c}\text { Transplantation of human fetal thymus, cord blood } \\
\text { and liver tissue for reconstitution of immune cell } \\
\text { populations. }\end{array}$ & [20] \\
\hline $\mathrm{B} 2 \mathrm{~m}$ null & $\begin{array}{l}\text { Deletion of Beta-2 microglobulin gene causes deficiency in } \\
\text { major histocompatibility complex (MHC) class I antigen } \\
\text { expression and function. Mice are deficient in CD8+ T } \\
\text { cells. }\end{array}$ & $\begin{array}{l}\text { Iron homeostasis, acute virus infection and } \\
\text { inflammation. }\end{array}$ & [23] \\
\hline $\begin{array}{l}\text { NOD-scid } \\
\text { IL2rynull }\end{array}$ & $\begin{array}{l}\text { Deletion of multiple genes causes severe impairment in T- } \\
\text { and B-cell development and absence of NK cells. }\end{array}$ & $\begin{array}{l}\text { Increased levels of growth, development and } \\
\text { differentiation of human pluripotent HSC and human } \\
\text { tissue engrafted by intravenous, intrahepatic, } \\
\text { intraperitoneal and intra-bone marrow injection. }\end{array}$ & {$[1,21,22,30]$} \\
\hline $\begin{array}{l}\text { NOD-scid- } \\
\text { B2mnull }\end{array}$ & $\begin{array}{l}\text { Deletion of multiple genes causes severe impairment in T- } \\
\text { and B-cell development and absence of NK cells. }\end{array}$ & Similar to NOD-scid IL2rynull. & {$[1,25,26,30]$} \\
\hline $\begin{array}{l}\text { HLA transgenic } \\
\text { mice }\end{array}$ & $\begin{array}{c}\text { Deletion of H2-Ab1 gene block the expression of MHC } \\
\text { class molecules A and E. }\end{array}$ & $\begin{array}{l}\text { Engraftment of human autoreactive T-cell clones } \\
\text { and identification of autoantigen. }\end{array}$ & {$[27,28]$} \\
\hline
\end{tabular}

[9]. The immune system of nude mice is characterized by a small population of $\mathrm{T}$ cells, an antibody response confined to IgM class, a low T-dependent response to antigens and an increased natural killer cell response. Consequently the rudimentary thymus produces a reduced number of mature $\mathrm{T}$ cells, with the result that homozygotes do not reject allografts and often do not reject xenografts as they mount no rejection response. However, the nude mice accumulate a small number of lymphocytes with T-cell antigens such as CD3, CD4, CD8 and Thy-1 which can be identified on the T cell surface with age. The population of mature CD8+ Tcells is cytolytically active and natural killer cells (NK) in nude mice are more potent than those from normal BALB/c mice. Nude mice are commonly employed for studies to test new methods of imaging and pharmacological treatment of human tumor xenografts $[1,7]$.
NOD Strains. Non-obese diabetic or NOD mice are a specially developed breed of mouse used as an animal model for type 1 diabetes [10]. The NOD mouse strain is also an excellent model of autoimmune disease and an important tool for dissecting tolerance mechanisms. The strength of this mouse strain is that it develops spontaneous autoimmune diabetes, which shares many similarities to autoimmune or type 1 diabetes (T1D) in human subjects, including the presence of pancreas-specific autoantibodies, autoreactive $\mathrm{CD} 4+$ and $\mathrm{CD} 8+\mathrm{T}$ cells, and genetic linkage to disease syntenic to that found in humans [11]. The incidence of spontaneous diabetes in the NOD mouse is $60 \%$ to $80 \%$ in females and $20 \%$ to $30 \%$ in males. Diabetes onset typically occurs at 12 to 14 weeks of age in female mice and slightly later in male mice. NOD mice harbor a unique major histocompatibility complex (MHC) haplotype, termed $\mathrm{H}-2^{\mathrm{g} 7}$ that is essential and is the highest genetic contributor for 
disease susceptibility. A polymorphism in the TNF- $\alpha$ and CTLA-4 gene also contributes to autoimmunity in NOD mice [11].

Scid Strains. The identification C.B-17 mouse strain mice with spontaneous agammaglobulinemia was followed by the discovery of mutation in Prkdc ${ }^{\text {scid }}$, a protein kinase DNA activated, or Scid mutation. This was the first severe combined immunodeficiency mouse strain described [12]. The DNA-dependent protein kinase (DNA-PK) is necessary for joining non-homologous ends of double-stranded DNA and this defect impairs the production of functional $\mathrm{B}$ and $\mathrm{T}$ cells, thus mice do not respond to either $\mathrm{B}$ or $\mathrm{T}$ cell mitogens. Nonetheless, functional $\mathrm{T}$ and $\mathrm{B}$ cells can be reconstituted after implantation of normal bone marrow. Some scid strains (C57BL/6J, Balb/c and CB-17) develop an immune reactivity and have low levels of one to three circulating levels of IgM, IgGs or IgA during aging that is know as scid leakiness. These mice serve as host recipient for transplants of human cells and organs and studies of human-mouse chimera interactions known as SCID-hu chimeras $[13,14]$.

RAG Strains. These mice are deleted in either ragl [15] or rag2 [16] recombination activating genes which are DNA recombinases involved in recognizing and cleaving signal specific sequences for somatic rearrangement of immunoglobulin (B cells) and $\mathrm{T}$ cell receptors. All known catalytic activities require the presence of both proteins. The RAG-2 knockout mouse model carries a germline mutation in which a large portion of the rag-2 gene-coding region is deleted. Deletion of the RAG-2 gene blocks B and T cell differentiation earlier and more completely than does the natural SCID defect [16]. Rag-deleted mice do no show the leakiness or radiosensitivity as observed in scid mice. Thus, loss of function of rag-1, rag-2 or Prkdc gene is sufficient to produce a mouse lacking both $\mathrm{T}$ and $\mathrm{B}$ cells. The main applications of RAG-2 mice are in the investigation of lymphocyte gene function in differentiation, AIDS and other immune deficiency diseases, the immune system's role in tumorigenesis and metastasis, and autoimmune and infectious diseases. RAG-2 is also used in chemotherapy studies and it is a possible alternative to both athymic (nude) and SCID mice $[1,7,16]$.

NOD/Scid Hybrid Strains. A better engraftment of human cells was achieved after the transfer of the Scid mutation onto the nonobese diabetic (NOD) mouse strains $[14,17]$. Importantly, the NOD/scid mouse does not develop diabetes. They have decreased natural killer (NK) cell activity and decreased innate immunity and can accept 10fold more human hematopoietic cells [14, 17]. NOD/scid mice implanted with human fetal thymic and liver organoids (BTL mouse) results in long-term, systemic human T-cell homeostasis [18]. These animals show extensive infiltration of organs and tissues with human cells, including liver, lung, and gastrointestinal tract. Thus BLT mice are adequately reconstituted with HIV-susceptible human CD4+ $\mathrm{T}$ cells and have been used for testing antiretroviral prophylaxis of vaginal HIV infection [19].

IL2 rg $^{-/-}$Strains. These mice are homozygous for targeted mutations at the interleukin-2 receptor (IL-2R) $\gamma$-locus IL2rg, also known as the common cytokine-receptor $\gamma$ - chain [20]. The IL-2R $\gamma$-chain is a crucial component of the high-affinity receptors for IL-2, IL-4, IL-7, IL-9, IL-15 and IL-21, and it is required for signaling through these receptors. The absence of the IL-2R $\gamma$-chain leads to severe impairments in T- and B-cell development and function, and completely prevents NK-cell development. The $\gamma$-component deficiency in mice is less severe than the Xlinked combined immunodeficiency disease (SCIDX1), which is lethal to humans [20]. The creation of IL2 $\mathrm{rg}^{-/}$ mouse strain has allowed the development of many alymphoid mice strains that are much less efficient in human cells and tissue rejection $[1,7]$.

NOD-scid IL2 rg $^{-/-}$Strains. A much better immunized mouse model came with the crossing of NOD/SCID mice and $I L 2 \mathrm{rg}^{-/-}$mice $[21,22]$. This hybrid model greatly improved the effectiveness of the engraftment of human tissues, PBMCs, stem and progenitor cells isolated from fetal liver, cord blood, bone marrow and PBMCs [21, 22]. For example, HSC engraftment in irradiated NOD $/$ scid $/ \mathrm{IL} 2 \mathrm{rg}^{-/}$ recipients allows the generation of both $\mathrm{T}$ and $\mathrm{B}$ cells that progress through the expected stages of intrathymic development [22]. Analyses of differentiation and cloning of human lineages of hematopoietic stem cells, including platelets, red blood cells and T-cell populations have been only possible in various models of immune-deficient IL2 $\mathrm{rg}^{-/-}$ mice $[1,21,22]$.

T and B Cell Deficient Transgenic Mice. There are several knockout mice models available for researches that do not generate mature $\mathrm{T}$ or B lymphocytes. These models include mice with doubly targeted mutations in rag- 1 or rag$2[15,16]$, and $\beta 2$ microglobulin (B2m) [23], or perforin (Prf1) genes [24] and hybrids mice crossed with NOD/scid strain [25]. Rag-1 and Rag-2 mutations prevent development of mature lymphocytes, and the $\mathrm{B} 2 \mathrm{~m}$ and Prf1 mutations prevent development and functional activity of mouse NK cells, respectively. The $\beta 2 \mathrm{~m}$ model is characterized by a deficiency in the expression of functional major histocompatability complex (MHC) class I molecules on the cell surface. The lack of MHC class I molecules disrupts the development of cytotoxic $\mathrm{T}$ cells and reduces $\mathrm{NK}$ cell function, whereas the $\mathrm{H} 2-\mathrm{Ab} 1$ model contains a disruption of the $\mathrm{H} 2-\mathrm{Ab} 1$ gene and expresses no $\mathrm{A}$ or $\mathrm{E}$ MHC class II molecules and therefore lacks most CD4+ $\mathrm{T}$ cells [25]. Human hematopoietic stem cell engraftment in the $\mathrm{NOD} / \mathrm{SCID} / \beta 2 \mathrm{~m}$ null and NOD/Rag1 null mice results in multiple myeloid lineages with moderate levels of differentiation. NOD/SCID mice reconstituted with human HSCs are proving useful for the study of EBV infection and tumor promotion, as these mice develop lymphoproliferative tumors, such as large B cell lymphomas, within a few weeks of infection with EBV [26].

HLA Humanized Transgenic Mice. Humanized HLAtransgenic mice are particularly useful in modeling human autoimmune diseases that are associated with specific human lymphocytes antigens of class I and II [27]. HLA-transgenic mouse models have been established for rheumatoid arthritis, relapsing polychondritis, experimental autoimmune encephalomyelitis, celiac disease, and Type 1 diabetes [27]. For example, HLA-DQ8 transgenic mice have rheumatoid factor, an antibody typically expressed only in rheumatoid arthritis patients, whereas this marker is absent in other animal models of this disease. Moreover, HLA-DQ8 mice 
display pathologies similar to those observed in nonhuman primates, including severe hypothermia and a massive surge of pro-inflammatory responses in the lungs, spleen, and serum. HLA-transgenic mice have also been used to identify epitopes of infection with staphylococcal enterotoxins [28].

A number of practical limitations still prevent the current models from serving as fully faithful host of human immune system $[29,30]$. It is expecting that the engraftment of human endothelium and the injection of growth factors and chemokines will improve these models by promoting the appropriate trafficking and expansion of human cells and modeling of T-cell response via the expressed HLA-antigen [30]. These improvements may allow the studies of lymphocyte-mediated vascular tissue remodeling, dysfunction, and destruction as well as responses to therapies and vaccines $[1,30]$.

\section{NEW GENOMIC AND BIOINFORMATIC APPROACHES FOR MOUSE MODELING OF IMMUNE DISORDERS}

Inbred mouse strains have provided uniform genetic background for accurate evaluation of specific genes phenotypes, thus eliminating the phenotypic variations caused by mixed genetic backgrounds. Over 450 inbred strains of mice have been developed with different genotypes and phenotypes based on genetic and immunological studies [31]. A large public effort to determine the complete sequences of over 15 inbred mouse strains is presently underway at Center for Rodent Genetics [htp://www.niehs.nih.gov/crg/cprc.htm, http://www.jax.org]. The most recent genomic sequences available are from mouse strains C57BL/6J, 129X1/SvJ, 129S1/SvImJ, A/J and DBA/2J [32, 33]. Because of interesting phenotype differences, the comparisons in these mice strain databases will provide a more powerful and efficient manner to identify polymorphic linkage maps to genes and regulatory regions of important Mendelian and non-Mendelian disorders.

The analysis of finished genome sequence of mouse has proved essential to understanding the full range of biology for both the mouse and human [33]. A mouse contains 20, 210 protein-coding genes, which is over a thousand than that predicted in the human genome, which is estimated in 19, 042 genes. Only $75 \%$ of mouse genes are in 1:1 orthologous relationships with human genes [33]. Despite huge differences between mouse and in human immunology, the mouse model provides ideal experimental system with which to dissect the genetic and biological complexities of the human disease-related phenotypes [34-36]. Experimental quantitative trait locus (QTL) analyses by multiple crosses and the chances of recombination of mouse inbred strains have provided a powerful method to localize chromosomal region harboring allelic variations that contribute significantly to disease severity in both mouse and humans [37]. Over 2, 000 QTL are listed in the Mouse Genome Informatics database [http://www.informatics.jax. org/menus], and many of these are relevant to human disease [38]. The primary aim of a QTL experiment is the identification of common DNA loci casually associated with a trait and likely the gene that may serve as key driver of disease or as the controller of genetic loci $[36,37]$. The method consists of crossing two strains and the effects of recombination in the following generations to the linkage (degree of co-variation) of polymorphic molecular markers and phenotypic trait measurements [htp://www.animalge nome.org/QTLdb]. Because most inbred mouse strains have a common ancestral heritage, the susceptibility alleles found in a QTL are primarily derived from the same ancestral allele of the causal gene, whereas the resistance might present in the alternative ancestral allele $[31,36,37]$.

A QTL found in one species is likely to be found in a second species in the homologous genomic location. Mouse/human homology maps showed very highly conserved regions [32, 33]. Experimental evidence from mouse and rat QTLs identified that $60-100 \%$ QTLs are concordant as diseases genes affecting human populations with hypertension, diabetes, asthma, inflammatory bowel disease and other disorders [2, 38-41]. For example, adducin 1 alpha [ADD1] for blood pressure, cytotoxic T-lymphocyte antigen 4 [CTLA4] for type 1 diabetes, cyclin-dependent kinase inhibitor $2 \mathrm{~A} / 2 \mathrm{~B}[\mathrm{CDKN} 2 \mathrm{~A} / 2 \mathrm{~B}]$ for type II diabetes, ORM1-like 3 [ORMDL3] for childhood asthma, complement factor $\mathrm{H}[\mathrm{CFH}]$ for macular degeneration, the tumor necrosis factor family member 4 [OX40] for atherosclerosis, caspase activation and recruitment domain 15 [CARD15] for inflammatory bowel disease and $\beta$-defensin-1 [hBD-1] for Crohn's disease and psoriasis are most common disease genes found in humans and rodent models [2, 38-41]. Overall, these investigations not only provide new insight into immune-linked disorders, but also highlight the importance of the genetic background in the predisposition to various illnesses.

New high- throughput technologies and the cumulative databases of the genome-wide SNP and copy number variations (CNVs) genotypes are now being used to reconstruct a reliable map of haplotype structures in human populations [http://www.ncbi.nlm.nih.gov/projects/SNP, http:// www.genome.gov/gwastudies/] as well as the inbred mouse strains [http://bioinfo.embl.it/SnpApplet/; http://www.hap map.org]. These databanks will dramatic increase the possibility to track polymorphisms and mutations linked to known QTLs. The mouse SNP miner database contains SNPs predicted to cause missense, STOP-gain, STOP-lost, frameshift, and splice-site mutations [42]. The use of several integrative bioinformatics tools, such as PolyPhen, PANTHER and eQTL [http://www.genetet-work.org] for in silico analysis of sequence databases is a powerful strategy that can be used in concert with experimental methods to narrowing QTL [43]. For example, Cervino and collaborators [43] developed a new in silico gene mapping strategy called QTG (quantitative trait gene) based in IBD (identical by descent) database from common ancestral mouse strain and new released 140,000 SNP maps of 48 mouse strains [http://www.broad.mit.edu] to compare and refine a region underlying QTL conserved in rodents. This strategy enabled them to narrow down the entire mouse genome to 3 potential gene-candidates that most likely influence cholesterol levels and 2 potential gene-candidates for hepatic fibrosis in rodents [43]. Nonetheless, it is not possible to know if the polymorphism in a QTL affects biochemical structure, function or expression of the genecandidate without using a laboratory animal model. 
Table 2. Examples of Web-Sites of Major Organizations and Institutions Providing Public Access to Databases, Computational Tools and Technology Platforms for Integrative Human and Mouse Genetic Research

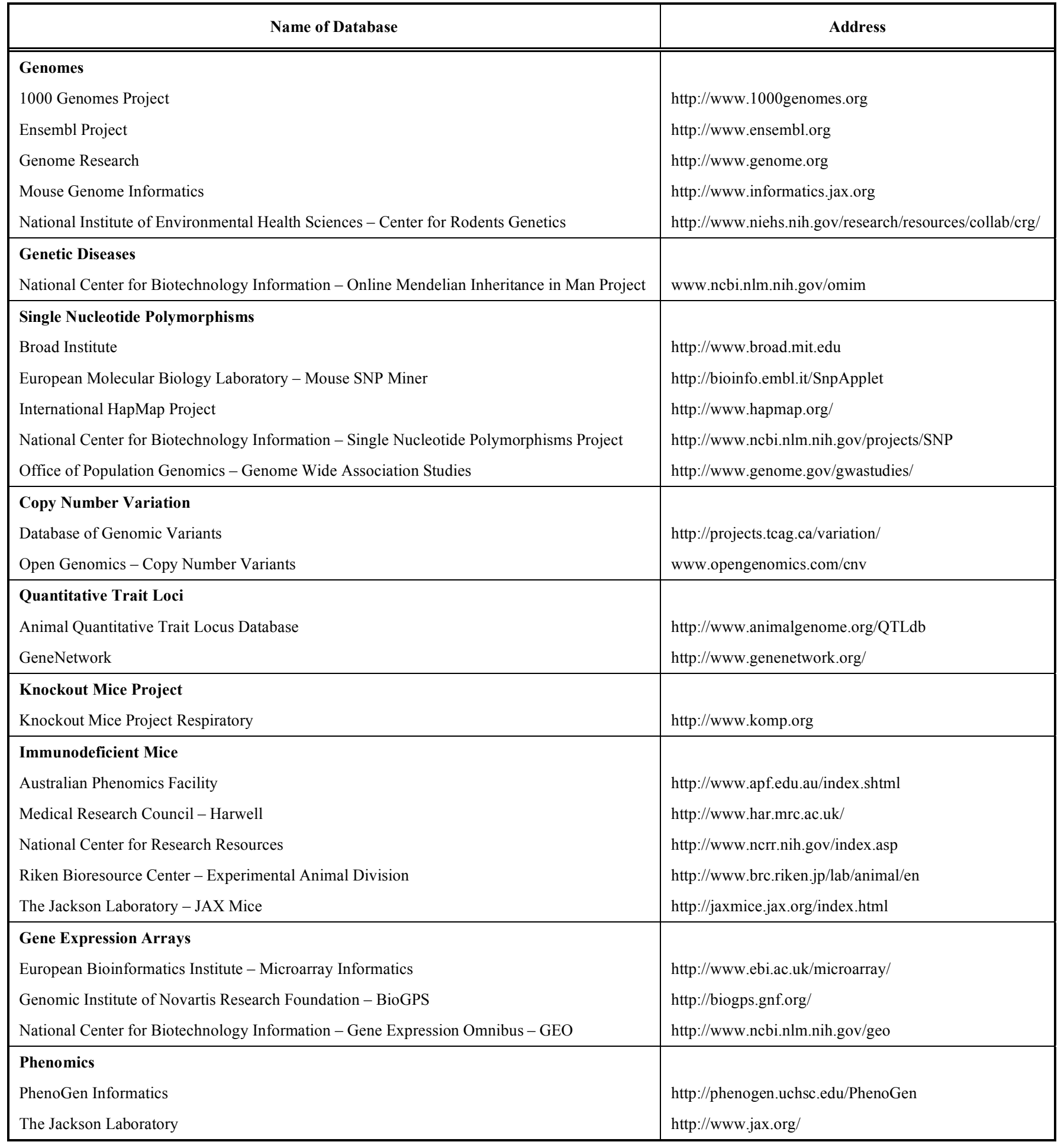

BAC libraries from many strains are now publicly available [http://bacpac.chori.org/]. Mapping of these BACs on the mouse genome should allow us convenient searching of mouse functional SNPs by strain, chromosomal location and predicted functional consequence of gene expression. This will greatly facilitate their utilization in homologous recombination-based intend to inactivating of the region of genomic DNA corresponding to QTL or candidate gene of a disease in knockout mice [44]. Furthermore, the Knockout Mouse Project [KOMP, http://www.komp.org] will generate a comprehensive and public resource containing the mouse embryonic stem (ES) cells with null mutation for the every gene in the mouse genome [44]. The identification of dispensable and indispensable genes (estimated in 15\% of genes) is the first step in defining the scale of the question of gene networks and individual differences. The mouse 
phenotype data from Mouse Genome Informatics [http://www.informatics.jax.org] has updated 1, 267 mouselethal human orthologs, of which 398 have known human disease associations ( $22 \%$ of human disease genes).

The novel genetic and bioinformatic methods to identify differentially expressed genes such as DNA, SNP microarrays and eQTL have provided a crucial step towards genome-wide transcriptional responses in mice models and human subjects undergoing an immune response [45]. Using these approaches it is possible to identify genes that interact with one another via the construction of a biological interaction network from microarray data. A network pathway is initiated by the gene with the highest specificity connection to a biological process [45]. A network of 1, 556 genes and their nodes and interactions in response to in vivo endotoxin administration to blood leukocytes has been described [46]. As expected, this study highlighted the interconnection and temporal relationship between several secreted pro-inflammatory cytokines and chemokines and their membrane receptors and several members of NF- $\kappa B$ transcription factors, which are well known players of innate immunity. In another report over 100 genes up- and downregulated were identified as critical modulators of allergic immune response to ovalbumin in a mouse model of asthma [47]. More recently, integrated computational methods for data mining and dynamic network analyses revealed the gene regulatory networks for the inflammatory response [48]. The results fit well with our current understanding that cooperative and interconnectivity of gene networks involving TLR family members (TLR2 and TLR4), TNFR and IL1R and NF- $\kappa b$ transcription factor play critical roles in innate immune response.

Table 2 shows a partial list of web-sites of organizations and institutions providing databank platforms and computational tools to access the human, mouse and rat whole genomes and examine virtually all genes and networks in cell types and tissues. It is also show a list of databases providing access to transgenic and immunedeficient mouse and their hybrids. Through the use and application of these diverse technology platforms, including expression microarrays, large-scale genome sequencing and functional genomics, it will be possible to design and construct specific mouse models and analyze their immune response in silico.

\section{CONCLUSIONS AND PERSPECTIVES}

The use of transgenic and immune-deficient mouse and their hybrids have served as important tool to study the immune system under normal and diseased conditions. The creation and utility of new immune-deficient mouse models will undoubtedly provide novel experimental approaches for understanding unrevealed mechanisms that appears to be centrally involved in the control of communication between the innate and acquired immune system and generation of distinct Treg cell lineages arising in tissue-specific autoimmunity, infections and cancer. Work in this field is just beginning, and genetically immune-deficient and HLAhumanized mouse models permitting the development of human lymphoid organs and tissue, should be particularly valuable tools for global genetic and immunological analysis of the functioning immune system as to the complexity in humans.

\section{ACKNOWLEDGEMENTS}

This work was supported by grant from Conselho Nacional de Desenvolvimento científico e Tecnológico (CNPq proc 452226/07/4) and International Centre for Genetic Engineering and Biotechnology (ICGEB-BRA0801).

\section{REFERENCES}

[1] Shults LD, Fumiko I, Greiner DL. Humanized mice in translational biomedical research. Nat Rev Immunol 2007; 7: 118-30.

[2] Akilesh S, Shaffer DJ, Roopenian D. Customized molecular phenotyping by quantitative gene expression and pattern recognition analysis. Genome Res 2007; 13: 1719-27.

[3] Baldwin TA, Starr TK, Hogquist KA. Mouse models of negative selection. $2^{\text {nd }}$ ed. In: Fox JG, Barthod SW, Davisson MT, et al., Eds. The mouse in biomedical research. Burlington: Academic Press 2007; pp. 303-13.

[4] Heissmeyer V, Tanasa B, Rao A. Peripheral tolerance of T cells in the mouse. $2^{\text {nd }}$ ed. In: Fox JG, Barthod SW, Davisson MT, et al., Eds. The Mouse in biomedical research. Burlington: Academic Press 2007; pp. 223-42.

[5] Liu K, Charalambous A, Steinman RM. Some biological features of dendritic cells in the mouse. $2^{\text {nd }}$ ed. In: Fox JG, Barthod SW, Davisson MT, et al., Ed. The mouse in biomedical research. Burlington: Academic Press 2007; pp. 135-54.

[6] Liu B, Shuai K. Cytokine-activated JAK-STAT signaling in the mouse immune system. In: Fox JG, Barthod SW, Davisson MT, et al., Eds. The mouse in biomedical research. $2^{\text {nd }}$ ed. Burlington Academic Press 2007; pp. 179-93.

[7] Croy BA, Di Santo JP, Manz M, Bankert RB. Mouse models of immunodeficiency. In: Fox JG, Barthod SW, Davisson MT, et al., Ed. The mouse in biomedical research. $2^{\text {nd }}$ ed. Burlington: Academic Press 2007; pp. 275-89.

[8] Flanagan SP. "Nude" a new hairless gene with pleiotropic effects in the mouse. Genet Res 1966; 8: 295-309.

[9] Nehls M, Pfeifer D, Schorpp M, Hedrich H, Boehm T. New member of the winged-helix protein family disrupted in mouse and rat nude mutations. Nature 1994; 372: 103-7.

[10] Kikutani H, Makino S. The murine autoimmune diabetes model: NOD and related strains. Adv Immunol 1992; 51: 285-322.

[11] Anderson MS, Bluestone JA. The NOD mouse: A model of immune dysregulation. Ann Rev Immunol 2005; 23: 447-85.

[12] Bosma GC, Custer RP, Bosma MJ. A severe combined immunodeficiency mutation in the mouse. Nature 1983; 301:52730 .

[13] Mosier DE, Gulizia RJ, Baird SM, Wilson DB. Transfer of a functional human immune system to mice with severe combined immunodeficiency. Nature 1988; 335: 256-9.

[14] Greiner DL, Hesselton RA, Shultz LD. SCID mouse models of human stem cell engraftment. Stem Cells 1998; 16: 166-77.

[15] Mombaerts P, Iacomini J, Jonhson RS, Herrup K, Tonegawa S, Papioannou VE. RAG-1 deficient mice have no mature B and T lymphocyte. Cell 1992; 68: 869-77.

[16] Shinkai U, Rathburn G, Lam K-P, et al. RAG-2 deficient mice lack mature lymphocyte owing to inability to initiate $\mathrm{V}(\mathrm{D}) \mathrm{J}$ rearrangement. Cell 1992; 68: 855-67.

[17] Shultz LD, Schweitzer PA, Christianson SW, et al. Multiple defects in innate and adaptive immunological function in NOD/LtSz-scid mice. J Immunol 1995; 154: 180-91.

[18] Melkus MW, Estes JD, Padgett-Thomas A, et al. Humanized mice mount specific adaptive and innate immune responses to EVB and TSST-1. Nature Med 2006; 12: 1316-22.

[19] Denton PW, Estes JD, Sun Z, et al. Antiretroviral pre-exposure prophylaxis prevents vaginal transmission of HIV-1 in humanized BLT mice. PLoS Med 2008; 4(12): e357.

[20] DiSanto JP, Muller W, Guy-Grand D, Fischer A, Rajewsky K. Lympoid development in mice with a targeted deletion of the interleukin 2 receptor $\gamma$ chain. Proc Natl Acad Sci USA 1995; 92: 377-81. 
[21] Ito M, Hiramatsu $\mathrm{H}$, Kobayashi $\mathrm{K}$, et al. $\mathrm{NOD} / \mathrm{SCID} / \gamma^{\mathrm{c}}$ nullmouse: an excellent recipient mouse model for engraftment of human cells. Blood 2002; 100: 3175-82.

[22] Ishikawa I, Yasukawa M, Lyons B, et al. Development of functional human blood and immune systems in NOD/SCID/IL2 receptor $\gamma$ chain null mice. Blood 2005; 106: 1565-73.

[23] Christianson SW, Greiner DL, Hesselton RA, et al. Enhanced human $\mathrm{CD} 4+\mathrm{T}$ cell engraftment in beta2-microglobulin-deficient NOD-scid mice. J Immunol 1997; 158: 3578-86.

[24] Kagi D, Ledermann B, Burki K, et al. Cytotoxicity mediated by T cells and natural killer cells is greatly impaired in perforin-deficient mice. Nature 1994; 369: 31-7

[25] Shultz LD, Banuelos S, Lyons B, et al. NOD/LtSz-Rag1nullPfpnull mice: a new model system with increaselevels of human peripheralleukocite and hematopoietic stem cell engraftment. Transplantation 2003; 76: 1036-42.

[26] Islas-Ohlmayer MA, Padgett-Thomas R, Domiati-Saad MW, et al. Experimental infection of NOD/SCID mice reconstituted with human CD34+ cells with Epstein-Barr virus. J Virol 2004; 78:13891-900

[27] Grusby MJ, Auchincloss H Jr, Lee R, et al. Mice lacking major histocompatibility complex class I and class II molecules. Proc Natl Acad Sci USA 1993; 90(9): 3913-7.

[28] Roy CJ, Warfield KL, Welcher BC, et al. Human leukocyte antigen-DQ8 transgenic mice: a model to examine the toxicity of aerosolized staphylococcal enterotoxin B. Infect Immun 2005; 73(4): 2452-60.

[29] Camacho RE, Wnek R, Fischer P, et al. Characterization of the NOD/scid-[Tg]DR1 mouse expressing HLA-DRB1-01 transgene: a model of SCID-hu mouse for vaccine development. Exp Hematol 2007; 35(8): 1219-30.

[30] Macchiarini F, Manz MG, Palucka, Shultz LD. Humanized mice: are we there yet? J Exp Med 2005; 202: 1307-11.

[31] Beck JA, Lloyd S, Hafezparast M, et al. Genealogies of mouse inbred strains. Nat Genet 2000; 24: 23-5.

[32] Flicek P, Aken BL, Beal K, et al. Ensembl 2008. Nucleic Acids Res (Database issue) 2008; 36: D707-14.

[33] Church DM, Goodstadt L, Hillier LW, et al. Lineage-specific biology revealed by a finished genome-assembly of the mouse. PLos Biol 2009; 7(5): e1000112.
[34] Hughes CCW, Mestas J. The mouse trap: how well do mice model human immunology. $2^{\text {nd }}$ ed. In: Fox JG, Barthod SW, Davisson MT, et al., Eds. The mouse in biomedical research. Burlington: Academic Press 2007; pp. 303-12.

[35] Konning DJ, Haley CS. Genetical genomics in human and model organisms. Trends Genetics 2005; 21: 377-81.

[36] Pennacchio LA. Insights from human-mouse genome comparisons. Mammalian Genome 2003; 14: 429-36.

[37] DiPetrillo K, Wang X, Stylianou IM, Paigen B. Bioinformatics toolbox for narrowing rodent quantitative trait loci. Trends Genetics 2005; 21(12): 685-92.

[38] Rahim NG, Harismendy O, Topol EJ, Frazer KA. Genetic determinants of phenotypic diversity in humans. Genome Biol 2008; 9: 215

[39] Casanova J-L, Abel L. Primary immunodeficiencies: a field in its infancy. Science 2007; 317: 617-9.

[40] Lee C, Morton C. Structural genomic variation and personalized medicine. New Engl J Med 2008; 358: 740-1.

[41] Manolio TA, Brooks LD, Collins FC. A HapMap harvest of insights into the genetics of common disease. J Clin Invest 2008 118: 1590-605.

[42] Reuveni E, Ramensky VE, Gross C. Mouse SNP Miner: an annotated database of mouse functional single nucleotide polymorphisms. BMC Genomics 2007; 8: 24e.

[43] Cervino ACL, Darvasi A, Fallahi M, Mader CC, Tsinoremas NF. An integrated in silico gene mapping strategy in inbred mice. Genetics 2007; 175(1): 321-33.

[44] Austin CP, Battey JF, Bradley A, et al. The knockout mouse project. Nat Genet 2004; 36(9): 921-4.

[45] Ekins S, Nikolsky Y, Bugrim A, Kirillov E, Nikolskaya T. Pathways mapping tools for analysis of high content data. Methods Mol Biol 2007; 356: 319-50.

[46] Calvano SE, Xiao W, Richards DR, et al. A network-based analysis of systemic inflammation in humans. Nature 2005; 437: 1032-7.

[47] Lu X, Jain VV, Finn PW, Perkins DL. Hubs in biological interaction network exhibit low changes in expression in experimental asthma. Mol Syst Biol 2007; 3: 98 .

[48] Chen B-S, Yang S-K, Lan C-Y, Chuang Y-J. A system biology approach to construct the gene regulatory network of systemic inflammation via microarray and databases mining. BMC Medical Genomics 2008; 1: 46 . 